\title{
Article
}

\section{An Animation Character Robot That Increases Sales}

\author{
Reo Matsumura ${ }^{1,2}$ and Masahiro Shiomi ${ }^{1, *}$
}

\author{
1 ATR, Kyoto 619-0237, Japan; reo@krkrpro.com \\ 2 Karakuri Products, Tokyo 103-0021, Japan \\ * Correspondence: m-shiomi@atr.jp; Tel.: +81-774-95-1432
}

check for updates

Citation: Matsumura, R.; Shiomi, M. An Animation Character Robot That Increases Sales. Appl. Sci. 2022, 12, 1724. https://doi.org/10.3390/ app12031724

Academic Editor: Elena Lazkano

Received: 18 December 2021

Accepted: 6 February 2022

Published: 8 February 2022

Publisher's Note: MDPI stays neutral with regard to jurisdictional claims in published maps and institutional affiliations.

Copyright: (C) 2022 by the authors. Licensee MDPI, Basel, Switzerland. This article is an open access article distributed under the terms and conditions of the Creative Commons Attribution (CC BY) license (https:// creativecommons.org/licenses/by/ $4.0 /)$.
Featured Application: Investigating the effects of a social robot on sales in shopping malls. A potential application is the design of social robot behaviors in scenarios where robots work as salesclerks in real shops.

\begin{abstract}
Performing the role of a shopping assistant is one promising application for social robots. Robot clerks can provide a richer experience for customers and increase sales; however, the scant opportunities for interaction with customers in real shopping environments is a typical drawback. We solve this problem by developing a unique networked salesclerk system that consists of a virtual agent that acts through the customer's smartphone and a physical agent that performs as a robot salesclerk in an actual store environment. Toward this capability, in cooperation with Production I.G. Inc., an animation production company, we adopted a character named Tachikoma from "Ghost in the Shell: Stand Alone Complex" (commonly known as the S.A.C. series) when designing the appearance and features of both agents. We conducted a field test to investigate how our system contributed to the sales of Ghost in the Shell anime-themed products, and the results showed the advantages of our system for increasing sales.
\end{abstract}

Keywords: robot salesclerks; Ghost in the Shell; Tachikoma

\section{Introduction}

\subsection{Research Aim}

Human-like behavioral expression design is an essential factor in creating acceptable social robots. Anthropomorphic behavior design would be an effective approach to achieving this goal because human beings treat anthropomorphic devices as if they were social agents [1]. Past studies have reported that several anthropomorphic behavior designs [2] such as facial expressions [3,4] play important roles in the perceived trustworthiness of social robots [5,6]. Other studies have also reported the importance of building social robots that are perceived as trustworthy in daily environments such as the home [7], industrial facilities [8], and shopping malls [9].

Social robots based on anthropomorphic behavior design are already beginning to fill the role of salespersons in daily environments. Many researchers have verified the capabilities of social robots as shopping assistants through field tests in real environments, in roles such as providing information in shopping malls [10-12] and stores [13-16], distributing flyers [17], and giving directions at airports [18-20]. Another human-friendly approach is to design a robot clerk that builds personal relationships with customers. Such systems perform, for example, recommendation services that leverage long-term interactions between customers and robot clerks. Several social robots have already been used in shopping malls for personalized interactions with customers. Using the interaction histories with customers in retail environments, personalized interaction can be achieved to create a more favorable impression on people [11,21]. Through these interactions, robot clerks can provide a richer experience for customers and can increase sales. 
However, robot salesclerks suffer from a typical drawback: scant opportunities for interaction with customers. Robot clerks are generally only present in real store environments and are too busy to interact frequently with customers. Even if a robot clerk provides a positive interaction and a pleasant shopping experience, the effect is diminished because there are few opportunities for them to interact with the customers. This lack of opportunities may also reduce customer interest.

We solve this problem by implementing a unique networked salesclerk system that consists of a virtual agent (computer graphics) acting through the customer's smartphone and a physical agent performing the duties of a robot salesclerk in an actual store environment. By using the virtual agent's characteristics for the physical agent in the store, we achieve a seamless and personalized cyber-physical interaction between customers and our robot salesclerk system. We partnered with Production I.G. Inc., an animation production company, and gained permission to use one of its characters, Tachikoma, from the Ghost in the Shell series. Consequently, we collaborated with this company in the design of the appearance and features of a robot clerk (Figure 1). We conducted several experiments in stores to determine how this robot salesclerk system would affect the sales of the target anime product, Ghost in the Shell. In this study, we addressed the following research question: Can a networked robot salesclerk created using an anime character increase the sales of that anime product?

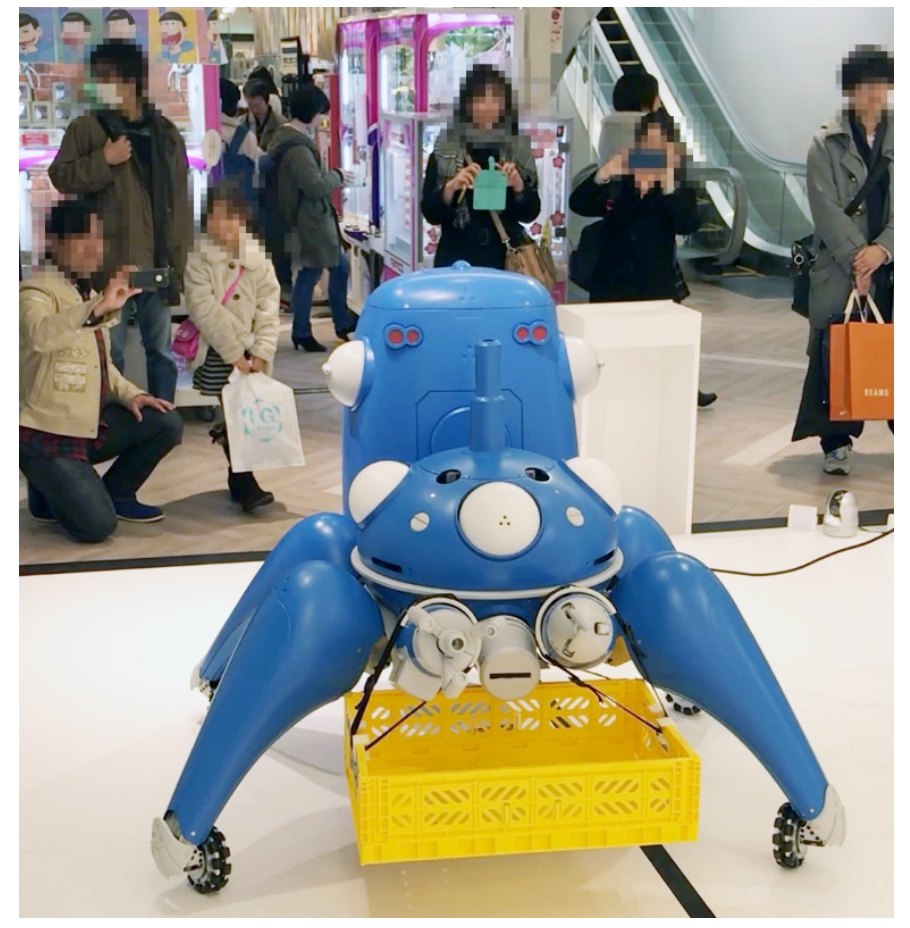

Figure 1. Physical agent whose appearance resembles Tachikoma.

\subsection{Related Work}

A number of studies have investigated the effectiveness of robot clerks in commercial establishments. Watanabe et al. reported the effectiveness of an android clerk system that talks through a tablet, in a department store for clothing sales [22]. Chao et al. developed a service robot system that provides information on multiple stores and distributes flyers in a shopping mall [23]. Another study investigated the effectiveness of self-recommending agents at shopping malls [24]. Another work investigated the effects of a robot recommendation system that distributed flyers for surrounding shops in a shopping center [15].

Although these studies provided rich knowledge about the effectiveness of robot clerk systems in real environments, they focused on physical agents. As a result, the opportunities for customers to interact with the robots were limited to physical shopping 
environments. In contrast to these studies, our research focuses on the impact of continuous interaction via cyber-physical systems on the sales in a physical store. For this purpose, we developed a networked robotic salesclerk that consists of both virtual and physical agents sharing the same personality.

The ITACO system proposed by Ogawa et al. [25] resembles our concept. Entities such as virtual agents, physical agents, and environmental devices interact with a peer through different interfaces in their system. In other words, the same personality is shared by different devices. The advantage of this design is that the characteristics of a single entity can be maintained across different interfaces. Since one of our goals is to build a personal relationship with customers, maintaining the characteristics of the same entity is critical.

Therefore, our approach, i.e., that of a virtual agent and a physical agent sharing the same characteristics, has common aspects with their work. However, our primary aim is not simply to evaluate this concept but rather to explore whether a networked robot salesclerk could actually increase the sales of the anime product used to embody the physical agent. For this purpose, we implemented a networked robot system that works in real environments with ordinary users. In other words, the unique feature of our study is the adaptation of this concept to actual shopping environments.

\section{Materials and Methods}

Because we were investigating the effectiveness of our proposed system in real shopping environments, we needed to address the design policies for a robot salesclerk system from two perspectives: shops and customers.

\subsection{Design Considerations from Shop Perspective}

We first discussed with shop managers which issues must be considered from their perspectives, before installing our robot salesclerk system in their shops. Based on several discussions, we chose four issues: appropriate contexts for customers, contribution to sales, safety, and simple operation.

As a suitable approach to placing a robot salesclerk in real shops, we designed the robot's appearance to resemble an existing animation character. Because a common business strategy to attract customers is using the characters from animation content, we felt that a robot might achieve similar effects and attract customers through its physical existence. We collaborated with Production I.G. Inc. and employed an animation character named Tachikoma from the "Ghost in the Shell" universe. Thus, the appearances and characteristics of the virtual and physical agents were based on Tachikoma. We presumed that this animation content would mainly attract a cohort whose ages ranged from about 20 to 50 years.

Next, we considered how our robot salesclerk system could contribute to the sales of animation merchandise. We believe that the novelty of providing rich shopping experiences to customers through interaction with animation characters will increase sales. Therefore, we used our robot system to encourage visits to an actual shop in order to physically interact with the customers who visited it. Thus, in our settings, the virtual agent recommends that customers reserve special merchandise that they can purchase at real shops.

We carefully designed the physical agent's functions for safety and simple operation since it interacts closely with customers during service, and managing it might prove difficult for a store's salesclerks. If a specialist/technician were needed to operate the robot, the system's cost would increase, thus reducing its benefits even if sales are increased. Moreover, complete autonomous control remains difficult in real environments, particularly in a shop where many customers surround a physical agent. Therefore, we chose a semiautonomous approach to enable control of the robot operation by non-experts, i.e., a shop employee, and limited its locomotion capabilities to prevent collisions. We also used a wired power supply and a network connection for safety. Based on these considerations, 
we ensured that the robot was safe by establishing physically separated areas and enabling non-experts to control or immediately stop the physical agent by themselves.

\subsection{Design Considerations from Customer Perspective}

We focused on two issues from the customer's viewpoint: personalized interaction and a memorable shopping experience. For personalized interaction with our robot salesclerk system, we designed our agents to greet the customer by name using our original voiceactor data and AI Inc.'s AITalk software [26]. Our system can change its characteristics based on interaction histories with customers and share these characteristics between the virtual and physical agents. For long-term interactions with customers, we also implemented a smartphone application (to maintain interaction) that has conversation-based games that include item-collection activities and chats about animation content.

For a memorable shopping experience, we used a physical agent that gives a customer's reserved merchandise to her/him in actual shops, as described above. The virtual agents in the game application offer to reserve animation merchandise through the application in the chat intervals. If customers reserve merchandise and visit the actual shops, they can transfer from their virtual agent to the physical agent who will distribute the merchandise. We believe such physical interaction with an actual robot viewed as an animation character will provide richer shopping experiences for customers and increase sales.

\subsection{System Configuration}

Figure 2 shows an overview of our system, which consists of a virtual agent on a smartphone, a physical agent at a real shop, a customer database (DB) on a server, and an operator. In the following subsections, we give details of each component.

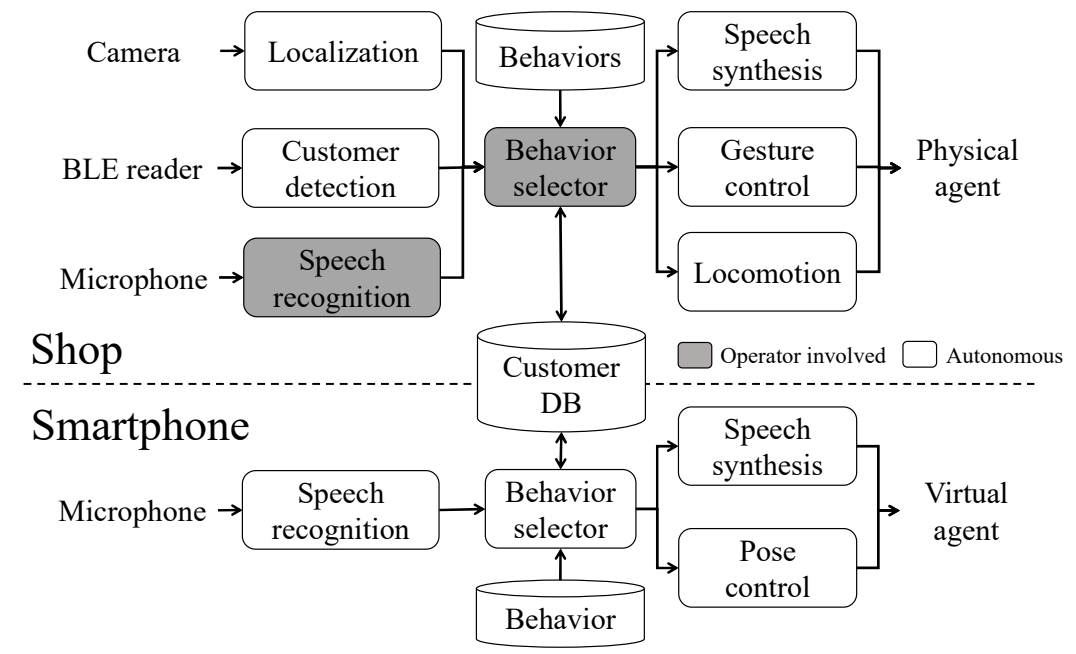

Figure 2. Example of a line task.

\subsection{Virtual Agent}

Figure 3 shows a virtual agent whose appearance and voice resemble Tachikoma. We implemented a game-like application where users can register their names to talk with the virtual agent. We implemented five tasks on this: chat, quiz, item collection, personalized interaction, and reservation. Thus, each virtual agent $\left(V A_{i}\right)$ has five tasks $\left(V A_{i_{-}} T=\left\{V A_{i_{-}} T_{1} \ldots V A_{i_{-}} T_{5}\right\}\right)$. These systems are designed to work on typical smartphone processors and OSs (i.e., iOS and Android, implemented using C\# and Unity for crossplatform development). However, during the experimental period, we only released the iOS version. Customers can choose each task $\left(V A_{i-} T_{1} \ldots V A_{i_{-}} T_{5}\right)$ directly via the application's user interface. 

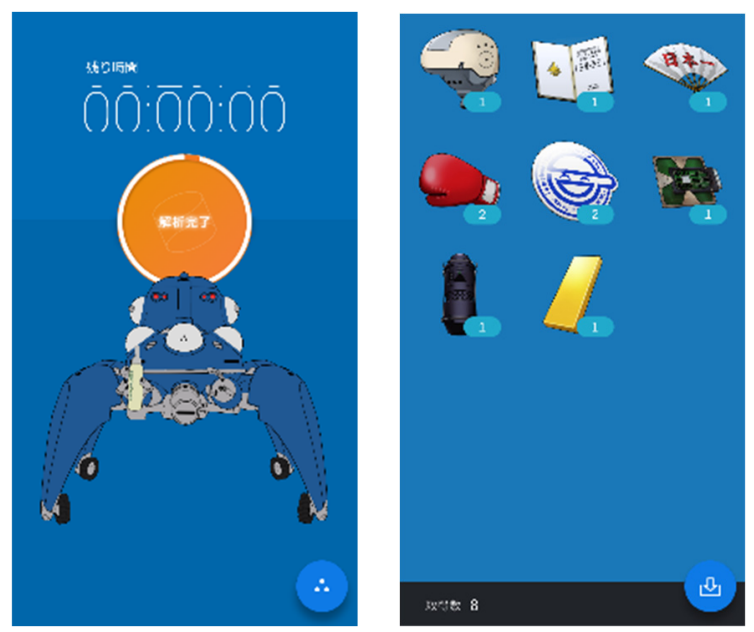

Figure 3. Virtual agent appearance and screenshots.

The chat task $\left(V A_{i-} T_{1}\right)$ enables the agent to talk autonomously with users. We recorded more than 1245 clips from Tachikoma's voice actor and implemented 691 conversation flows such as greetings, information on animation characters, and the reproduction of animation scenes (i.e., 691 actions in this task). For example, during a chat, the virtual agent might say, "Even though Japan is a robot powerhouse, that idea expresses overconfidence in Japan's technology." We used Google's speech recognition functions for this task.

The quiz task $\left(V A_{i_{-}} T_{2}\right)$ enables the agent to ask questions based on Ghost in the Shell: S.A.C. The content was selected under pre-implemented rules such as having a specific item. If a user correctly answers the questions, additional voice data are provided to the user. For this purpose, we implemented more than 40 questions (i.e., 40 actions in this task) in the application, for example, "What does Harima Science Garden City mean to Tachikoma?".

The item-collection task $\left(V A_{i-} T_{3}\right)$ enables users to amass 51 items related to Ghost in the Shell: S.A.C. through an analysis process that must wait for a specific time period. Users can spend the items they have collected to change the appearance of their virtual agent or access extra quiz content. We shortened the waiting time for the analysis process by creating an option that allows users to buy special items with reduced waiting time.

The personalized-interaction task $\left(V A_{i-} T_{4}\right)$ changes its characteristics based on the conversations and the histories of the item collections. We designed three characteristics: polite, friendly, and ironic $\left(V A_{i_{-}} C=\left\{V A_{i_{-}} C_{1} \ldots V A_{i_{-}} C_{3}\right\}\right)$. Due to these characteristics, the robot changes its word endings and intonations (i.e., three actions in this task, where these actions also influence other tasks). The virtual agent's characteristics also influence the interactions with the physical robot in the shop environment.

The reservation task $\left(V A_{i-} T_{5}\right)$ announces when its services will start for the animation merchandise in a real shop, and then it allows users to reserve items (i.e., two actions in this task). For this purpose, the virtual agent verbally recommends buying items: "If you are interested, I can reserve some cool merchandise for you" or "I've got some new information about special merchandise!" If the users want to buy any animation merchandise, they can reserve it with this task and set a date to buy it at the actual shop. Significantly, customers can interact with their virtual agents using the smartphone application after the field trials, regardless of whether or not they buy merchandise.

\subsection{Physical Agent}

Figure 1 shows a robot salesclerk as our physical agent $(P A)$. It resembles a smaller version of Tachikoma: $1600 \times 1600 \times 1100 \mathrm{~mm}$ with two arms (14 degrees of freedom). We attached a camera, a microphone, and a speaker to the robot. We used NUC5i7RYH (Intel Corporation, Santa Clara, CA, USA) for the physical agent's controls and its processing. 
We also used VS-RC003D (MCU: LPC2148F, Vstone Co., Ltd., Osaka, Japan) for the motor control of the physical agent. We implemented four tasks for the agent: locomotion, person identification, handing things, and conversation. Thus, the physical agent $(P A)$ has four tasks $\left(P A_{-} T=\left\{P A_{i-} T_{1} \ldots P A_{i-} T_{4}\right\}\right)$. For safety, the power supply and network connection were wired. We used voice data identical to those of the virtual agent.

For the locomotion task $\left(P A_{-} T_{1}\right)$, the robot operates under semi-autonomous control. Locomotion is mostly autonomous, with a line-tracing mechanism operating at $60 \mathrm{fps}$. After a command from the operator, the robot autonomously detects a line on the floor and changes the speed of its wheels to follow it. We made two stopping points: in front of visitors and in front of where the shopkeeper hands items to the robot (i.e., two actions in this task). During experiments, we installed the physical agent on a temporary stage (about $4.5[\mathrm{~m}] \times 5.5[\mathrm{~m}])$ in the experimental environments.

For the identification task $\left(P A_{-} T_{2}\right)$, we used customers' smartphones to identify them. When a customer places his smartphone (after downloading the application) on a stand where the Bluetooth Low Energy (BLE) reader is installed (Figure 4a), the system is notified that the virtual agent is to be transferred to the physical agent. The virtual agent on the smartphone disappears, and the physical robot starts working. At this time, the characteristics of the physical agent are copied from the virtual agent $\left(P A_{-} C=V A_{i-} C x\right)$. When the smartphone moves away from the stand, the virtual agent is automatically shown returning to the smartphone (i.e., two actions in this task).

If the customer has reserved a purchase, the physical agent executes the handing over task $\left(P A_{-} T_{3}\right)$; the physical agent greets the customer, moves to the storage area, and takes the purchased item from the clerk (Figure $4 \mathrm{~b}$ ), and then it moves toward the customer and hands her the item (Figure $4 \mathrm{c}$ ) (i.e., four actions in this task).

The conversational task $\left(P A_{-} T_{4}\right)$ is also performed under semi-autonomous control. The operator assumes the voice recognition function and selects the robot's voice speech buttons based on the pre-defined rules. If a customer has registered for the application, the robot can use this. Using the dialogue history between the virtual agent and the customer, we designed the robot to change its speech content automatically. We prepared 58 speech-content items.

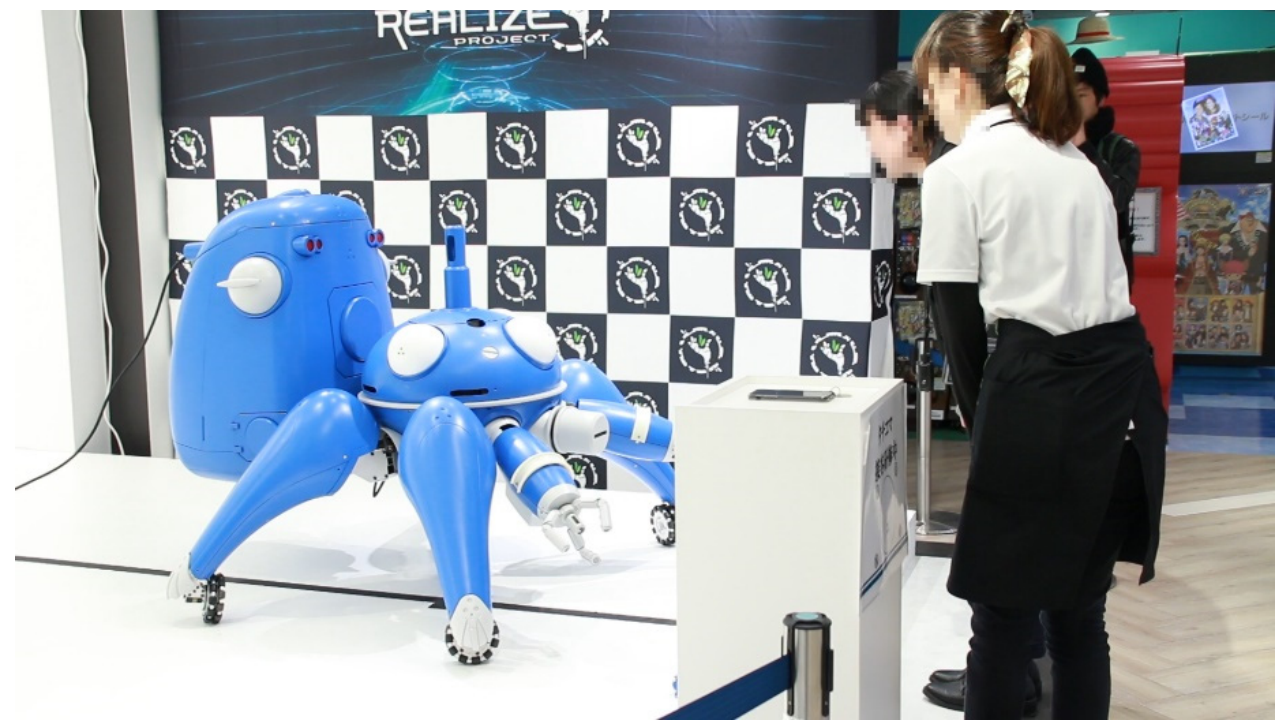

(a)

Figure 4. Cont. 


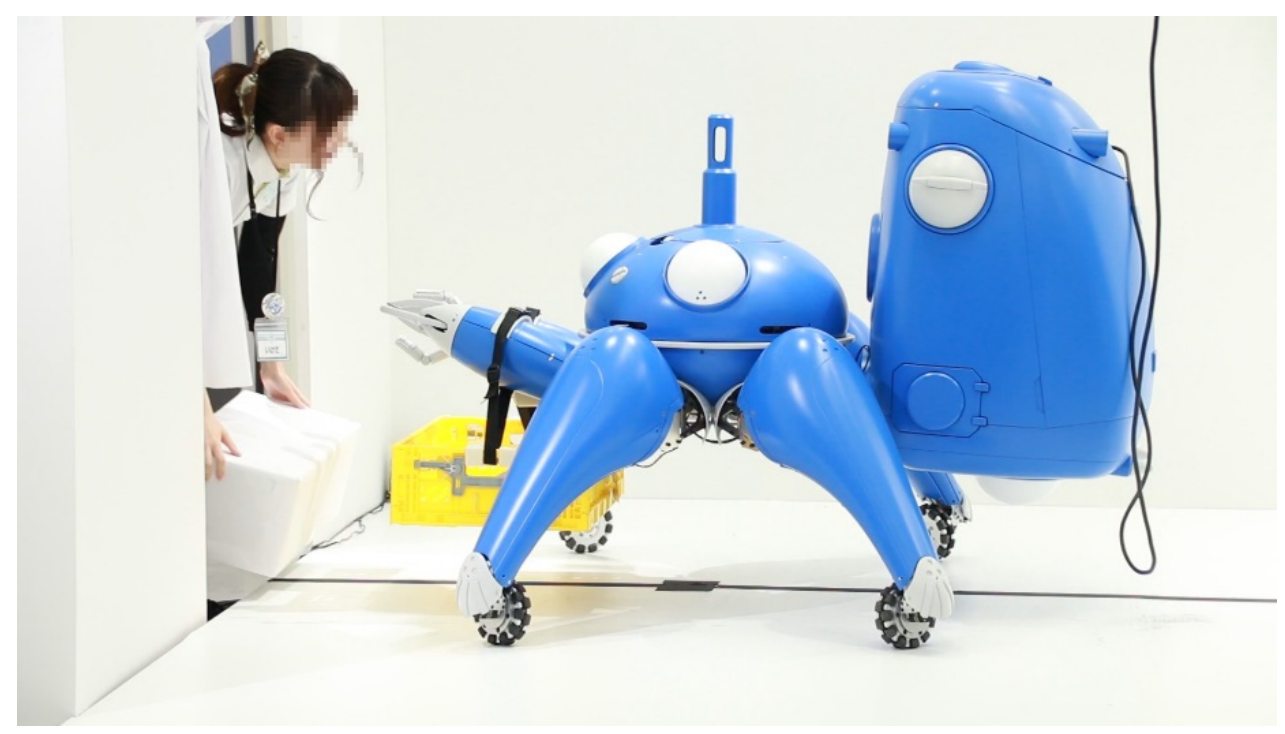

(b)

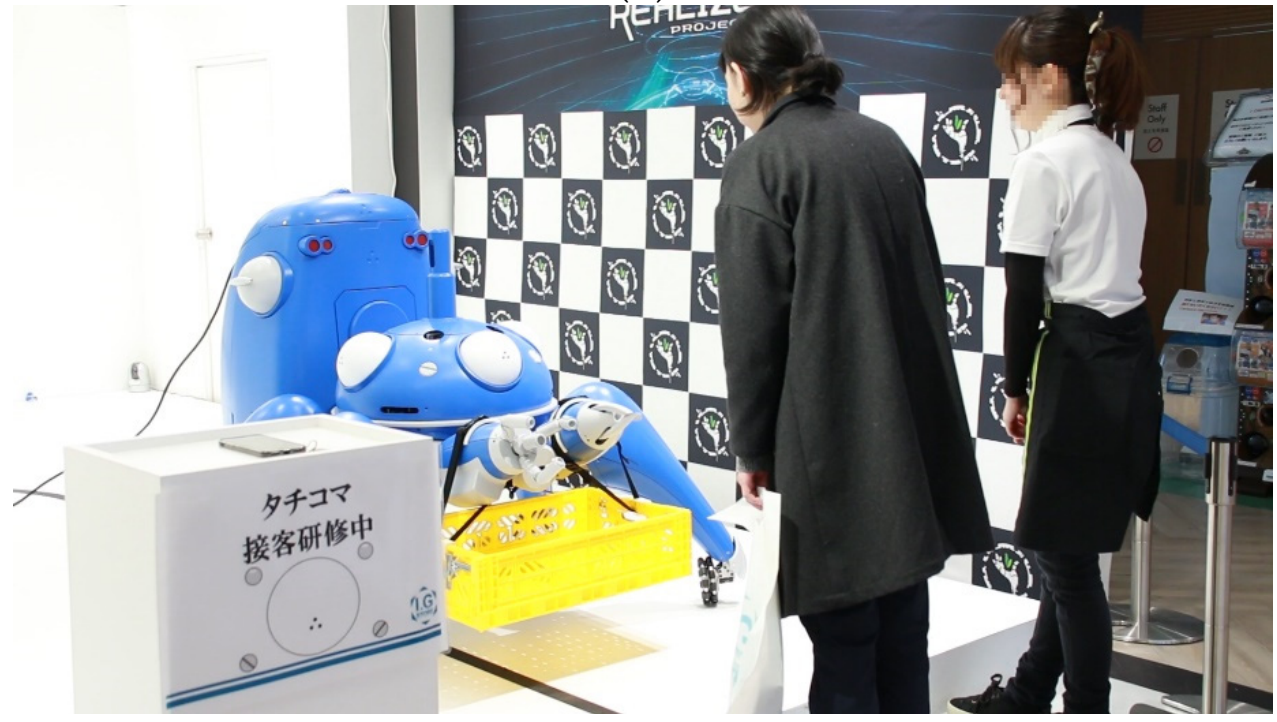

(c)

Figure 4. Giving a purchased item to a customer. (a) The physical agent greets to the customer; (b) The physical agent takes the purchased item from the clerk; (c) The physical agent hands the customer's the item.

\subsection{Operator}

In this study, an operator controls the speech recognition function and the behavior selector using a tele-operation system (Wizard of Oz [27]), which enables the operator to select the speech recognition results based on pre-determined candidates. Then the physical agent autonomously chooses actions using the speech recognition results. The average distance between customers and the physical agents is about $1 \mathrm{~m}$ while they are talking, as shown in Figure 4. Accordingly, the operator can hear the customers' speech and recognize it correctly, using the microphone attached to the agent. We also used NUC5i7RYH (Intel Inc.) for the tele-operation.

The operator assumes control of the safety function of the physical agent's locomotion and an emergency stop function (not used during the experiment). Basically, the agent moves autonomously using the line-tracing mechanism, although the operator corrects its position through the tele-operation system if the agent loses track of the line. In addition, another shop clerk monitored the system for safety during the experiment. 
If customers want to chat with the physical agent, the operator directly chooses robot behaviors for natural interaction with these customers. We prepared pre-determined rules for consistent operation and for retaining the physical agent's characteristics.

\subsection{Customer $D B$}

The customer DB is connected to both the virtual agents in the customers' smartphones and the physical agent. All the interaction histories and the characteristic data are stored in the $\mathrm{DB}$, and this information is used for the interactions between the virtual/physical agents and the customers. The reservation information is also transferred to the shop clerks and the operator, who prepare the reserved merchandise for the customers.

\section{Field Trial and Results}

We conducted field trials with our robot salesclerk system at three different shops to investigate two issues: (1) a comparison of sales between the time period of the field trial and the shop's long-term history to investigate our system's influence and (2) whether our system could be installed in different kinds of shops to increase sales, even for temporary sales spaces.

\subsection{Field Trial for Sales Comparison}

The first field trial was conducted at a Production I.G. store in Tokyo that sells a variety of animated goods. We installed a physical agent and a stand in the store and measured the sales effects for 14 consecutive days in the middle of Japan's winter holiday season. We released the application 18 days before the demonstration experiment and announced the start of the user reservation service through the application 11 days before the demonstration experiment.

In the experiment, the physical agent was placed in the store between 11:00 a.m. and 8:00 p.m. Customers who reserved products were given their choice of four 15-min time slots per hour to interact with the physical agent after receiving their reserved products. During time slots without reservations, the operator manipulated the physical agent to greet nearby customers or interact with them.

\subsection{Results of Sales Comparison}

During the field test period, the daily sales of the target anime products averaged about JPY 86,450 (about USD 760), with a median of about JPY 81,680 (about USD 720). We measured the sales for two time periods: 14 consecutive days in the middle of the summer holiday season and during the first six months that the store was open. The first time period was used to statistically compare sales between similar holiday time periods, since the middle of the summer holiday season is an extremely busy period. In these periods, the store was open between 11:00 a.m. and 8:00 p.m., similar to the operating hours of our field trial. Note that direct sales comparisons cannot avoid such factors as new merchandise and commercial events; however, even though the implications of the comparisons are limited, they still provide supplemental knowledge.

The average daily sales of the target animation merchandise were JPY 40,025 (about USD 400) over 14 days during the middle of the summer holiday season (Figure 5). Since Levene's test did not show any significant differences between them, we conducted a $t$-test for comparison, and its results showed significant differences $(t(26)=3.814, p=0.001$, $r=0.60$ ). Thus, the average sales in our field trial were significantly larger than the average sales during the normal summer holiday season.

For the second period, we also measured the mean and median values. We chose this time period because the store hosted several different events, which made this period suitable for identifying the long-term sales trends of our target anime products. The average daily sales for the target anime products were JPY 43,041 (about USD 380), with a median of JPY 30,630 (about USD 270). We did not conduct a statistical analysis because the number of days differed considerably. However, the results showed that the average and median sales 
were 2.01 and 2.67 times higher than those without the salesclerk system. These results indicate that our robot salesclerk increased the sales of the target animation merchandise.

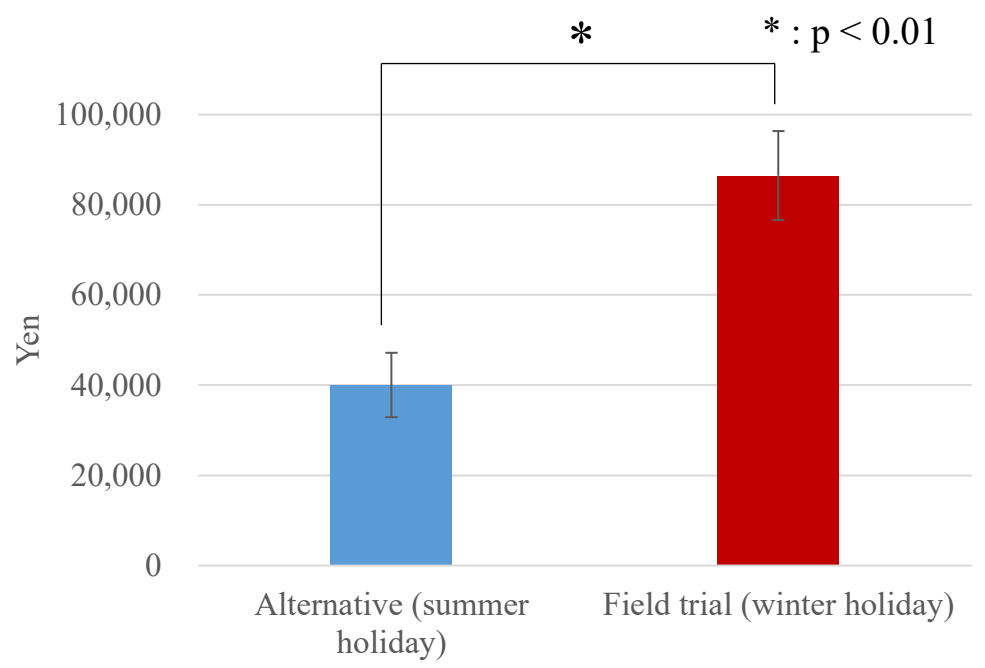

Figure 5. Average and standard error (SE) of daily sales of target animation merchandise at a Production I.G. store in Tokyo.

\subsection{Field Trial in Temporary Sales Spaces}

After the field trial in Tokyo, we conducted two more trials at a pair of Osaka shopping malls. Since they were conducted using temporary sales spaces in the mall, it was difficult to compare the sales in the time period of the field trial with past sales. Moreover, in these shops, only four kinds of animation merchandise were sold, due to the shops' small sizes.

The first trial was conducted at a large shopping mall for 12 consecutive days from 11 a.m. to 8 p.m. The second was conducted at another shopping mall (the tallest shopping building in Japan) for 10 consecutive days from 2 to 8 p.m. (weekdays) or 11 a.m. to 8 p.m. (weekends).

\subsection{Results for Temporary Sales Spaces}

In the two field trials in Osaka, the robot salesclerk systems worked well, showing similar performance as in the Tokyo field trial. The average daily sales of the target animation merchandise in the two trials were JPY 40,611 (about USD 375) and JPY 51,082 (about USD 472). Sales at temporary sales spaces achieved similar average sales during the summer holiday season.

Moreover, since these temporary shops sold only four kinds of animation merchandise, we investigated the sales ratio of the target animation merchandise to all merchandise. These values indicate how our robot system contributed to sales. The ratios with total sales were $54.7 \%$ and $81.3 \%$ in the two trials.

\subsection{Interaction with Virtual Agents}

Next, we investigated how many people downloaded our application and used its reservation tasks. During the field trials, 12,140 users downloaded the application. We also investigated the average daily use of active users during the trial and identified 834 users, with an average number of active sessions (identified as over two seconds of foreground on their smartphones) of 8504. These results indicated that each active user accessed our application more than ten times per day on average.

Over 200 customers bought target animation merchandise through the reservation services. In fact, 2504 customers reserved merchandise, but due to the limitations of the time slots (including temporary reservations), only 208 customers actually bought the merchandise at the shop. 
Although many customers used our application, they might have failed to perceive changes in the characteristics of the virtual agents because they did not have any opportunity to compare their agents with other agents in the shop that had different characteristics.

\subsection{Observations in the Shop}

During the $15 \mathrm{~min}$ time slots, about $10 \mathrm{~min}$ were generally allotted for distributing the reserved merchandise to customers. In the remaining $5 \mathrm{~min}$, as we expected, the customers talked with the physical agent until the end of their time slot. They seemed to enjoy their interactions with the animation character, and most people wanted to talk with it beyond their allotted time slot. If other customers were not waiting, they were allowed to extend their conversations.

In general, since most customers were already familiar with Tachikoma and the Ghost in the Shell: S.A.C. series universe, they asked the physical agent specific, game-oriented questions. For example, many customers asked, "What is your favorite item?", and the answer was "Organic Oil". They also seemed interested in testing the robot's intelligence, as in previous research studies $[28,29]$. In addition, customers often asked about Motoko Kusanagi, also known as the Major, Tachikoma's boss, and enjoyed the agent's reactions. After interacting with the physical agent, most customers wanted to take a picture with it, often accepting an invitation to take photos from the physical agent (Figure 6).

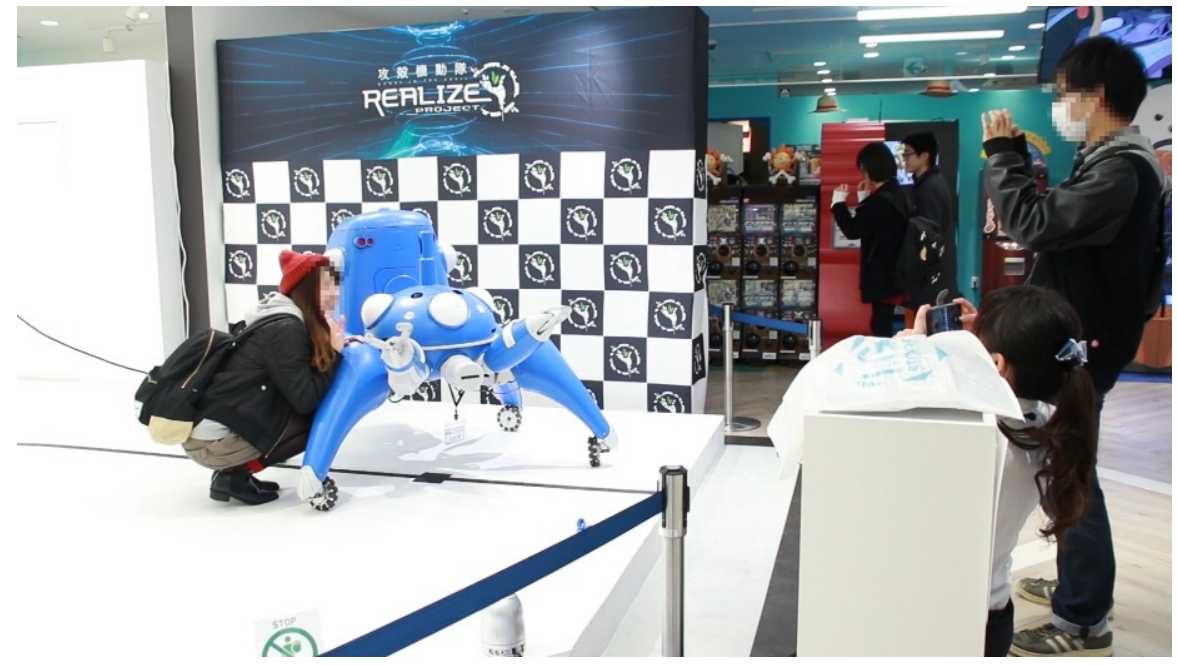

Figure 6. Customers taking a picture with physical agent.

Another interesting phenomenon was how the physical agent was frequently treated as a physical landmark by the customers. From our observations in the field trials, many people arranged to meet near Tachikoma because of its conspicuous size. As in previous research studies, our physical agent might also have been useful as a shop mascot [9].

It should be noted that we did not evaluate the effects of virtual agents' characteristics (polite, friendly, or ironic) in the context of sales or relevant customer reactions, due to the limitations of the time slots for reservation services, although we implemented the different characteristics. As described above, only 208 customers actually used the system to buy merchandise at the shop, and we believed that making an evaluation with such a limited number of people (less than $10 \%$ of customers who reserved merchandise) would not be worthwhile. Nevertheless, customers seemed to enjoy themselves, regardless of their agents' characteristics, as described above. We attributed this to the closely reproduced variety of characteristics based on the animation character (in the original animation, multiple incarnations of Tachikoma have different characteristics). 


\section{Discussion}

\subsection{Engineering Perspective: Can It Be Autonomous?}

In this study, we designed a semi-autonomous physical agent from the perspectives of safety and managing operations. Future technical challenges include increasing its autonomy and reducing the human operation load. For example, safe movement in crowded places is a central task of many current research studies. Robotics researchers have proposed several methods for enabling robots to move safely, even in crowded areas, using multiple types of sensor information and applying societal norms [30-33].

Individual identification functions would be needed to achieve long-term autonomous interaction with customers. In this study, we used BLE signals from a smartphone to identify people. If a robot clerk moves around, the robot itself needs to be equipped with the ability to perform personal identification. In the past, research has used RFID tags, Wi-Fi, accelerometers [34,35], and face recognition software for such identification. Although privacy issues must be heeded, personal identification might be possible using such technologies.

Speech recognition is another challenging problem in real-world environments. Although various speech recognition technologies have been developed in recent years, actual environments contain a great deal of noise, and there are large distances between the microphones attached to the robot and people. Therefore, significant improvements in the performance of voice recognition technology in smartphones and PCs in such settings seem unlikely. Moreover, adding new data for training is a crucial first step in improving speech recognition performance in real environments.

Further future work could involve using machine learning techniques to improve robots' behaviors based on interaction histories and feedback from interacting partners. For example, Millán et al. proposed a method of incorporating human feedback in reinforcement learning for a continuous action space [36]. Doering et al. also proposed a data-driven imitation-learning approach for shopkeeper robots [37]. In the context of conversational interactions related to selling merchandise to customers using autonomous conversational functions, the agents would need to explain the meaning and intention of their behaviors, since these influence users' decision-making [38,39]. Such a machine-learning-based approach would improve robot motion control performances [40] related to their safety and locomotion [41,42].

\subsection{Commercial Perspective: Should It Be Fully Autonomous?}

In the above section, we discussed ways to achieve autonomous systems by considering related technologies. Although these trials are important for fully autonomous agents, we need to consider this goal from a business perspective by addressing two problems: safety and cost. With regard to safety, it remains difficult to completely eliminate the requirement that physical robots be monitored by the shop employees using them in public spaces, even if a sufficient degree of safety is ensured. The responsibilities for failures/accidents are not yet well defined, especially for mobile agents such as autonomous driving cars, and therefore such responsibilities usually fall on manufacturers or management companies. To avoid worst-case scenarios, a human observer must guarantee the safety of an agent in our current social settings. If a shop employs a robot salesclerk system, the initial cost is critical. Perhaps fully autonomous systems might be able to use rich sensor environments, but this also, unfortunately, increases the initial implementation costs.

In this study, we used a semi-autonomous approach in which a human operator ensured safety and controlled parts of the sensing/controlling functions for serving customers. This approach was restricted to a single shop employee as the operator, although our robot system provided more memorable shopping experiences than those of standard services by a shop clerk. We believe our approach is cost-efficient and can preserve safety in actual settings in current situations, because past research has shown that a single operator can control four or more mobile social agents in a mall environment $[43,44]$. In the 
future, of course, the operator's role and workload will decrease along with the progress of sensing technologies.

\subsection{Limitations}

Since our field trials were conducted with our developed agents and for specific animation characters, the generality of the knowledge obtained was limited. We cannot ensure that our findings can be applied to other kinds of robot salesclerk systems with different animation contents. Moreover, it is difficult to clearly investigate the effects of a robot salesclerk system by comparing situations with/without their use at actual shops because the value and the popularity of animation merchandise fluctuate. However, we believe our setting can still offer essential knowledge to readers who are interested in the effects of robot salesclerks.

We did not evaluate the degree of memorability of the shopping experience using questionnaires from customers because it was difficult to compare their shopping impression with/without our systems while avoiding unfair services during the experimental period. We noted that many customers enjoyed their shopping experiences with the agents, as described in Sections 3.5 and 3.6. Therefore, we believe that the issues under focus from the customers' perspectives were successfully addressed.

Since our field trial only lasted about a month, the long-term and novelty effects of physical agents on sales remain unknown. Nor have we yet identified the effects of the changes in personalized characteristics of virtual and physical agents because few people noticed them. To clarify these effects, we are currently conducting a long-term field trial in a shop in Tokyo, by permanently providing reservation services through our robot salesclerk system. In addition, our analysis compared sales in the field trials between summer holidays and winter holidays. Both holiday seasons have positive effects when inviting customers to the shop, but it is difficult to reveal such time-based influences on sales. Future work in this study will be to obtain long-term operation results and then investigate the effects of characters by eliminating these seasonal effects.

\section{Conclusions}

We developed a robot salesperson system in which the same personality could be shared in an actual store environment by a virtual agent on a smartphone application and a physical agent embodied in a robot. Furthermore, we verified this system's effectiveness. In collaboration with an anime company, we adopted the design of a character named Tachikoma as a robot salesclerk. The results of a field trial in an actual store demonstrated that the presence of the robot clerk more than doubled the average daily sales of the targeted anime products. More than 12,000 customers downloaded our application to their smartphones, and about 200 customers visited the shop used in the trial to buy merchandise and interact with our physical agent.

Author Contributions: Conceptualization, R.M.; data curation, R.M. and M.S.; formal analysis, M.S.; funding acquisition, M.S.; investigation, M.S.; methodology, R.M.; project administration, R.M.; resources, R.M.; software, R.M.; supervision, R.M.; validation, R.M.; visualization, M.S.; writingoriginal draft preparation, M.S.; writing — review and editing, R.M. and M.S. All authors have read and agreed to the published version of the manuscript.

Funding: This work was supported by JST CREST, Grant Number JPMJCR18A1, Japan.

Institutional Review Board Statement: The study was approved by the ethics committee at the Advanced Telecommunication Research Institute (ATR) (21-521).

Informed Consent Statement: Informed consent was obtained from all subjects involved in the study.

Data Availability Statement: The data presented in this study can be obtained on request from the corresponding author. 
Acknowledgments: We thank the salesclerks who supported our experiments.

Conflicts of Interest: The authors declare no conflict of interest. The funders had no role in the design of the study, in the collection, analyses, or interpretation of data, in the writing of the manuscript, or in the decision to publish the results.

\section{References}

1. Reeves, B.; Nass, C. The Media Equation: How People Treat Computers, Television, and New Media Like Real People and Places; CSLI Publications and Cambridge University Press: New York, NY, USA, 1996.

2. Natarajan, M.; Gombolay, M. Effects of anthropomorphism and accountability on trust in human robot interaction. In Proceedings of the $2020 \mathrm{ACM} / \mathrm{IEEE}$ International Conference on Human-Robot Interaction, Cambridge, UK, 23-26 March 2020 ; pp. 33-42.

3. Song, Y.; Luximon, A.; Luximon, Y. The effect of facial features on facial anthropomorphic trustworthiness in social robots. Appl. Ergon. 2021, 94, 103420. [CrossRef] [PubMed]

4. Song, Y.; Luximon, Y. The face of trust: The effect of robot face ratio on consumer preference. Comput. Hum. Behav. 2021, 116, 106620. [CrossRef]

5. Song, Y. Building a 'Deeper'Trust: Mapping the Facial Anthropomorphic Trustworthiness in Social Robot Design through Multidisciplinary Approaches. Des. J. 2020, 23, 639-649.

6. Law, T.; de Leeuw, J.; Long, J.H. How Movements of a Non-Humanoid Robot Affect Emotional Perceptions and Trust. Int. J. Soc. Robot. 2021, 13, 1967-1987. [CrossRef]

7. Sack, O.; Röcker, C. “Like a Family Member Who Takes Care of Me” Users' Anthropomorphic Representations and Trustworthiness of Smart Home Environments. J. ISSN 2014, 2368, 6103. [CrossRef]

8. Onnasch, L.; Hildebrandt, C.L. Impact of Anthropomorphic Robot Design on Trust and Attention in Industrial Human-Robot Interaction. ACM Trans. Hum. Robot. Interact. 2021, 11, 1-24. [CrossRef]

9. Sabelli, A.M.; Kanda, T. Robovie as a Mascot: A Qualitative Study for Long-Term Presence of Robots in a Shopping Mall. Int. J. Soc. Robot. 2016, 8, 211-221. [CrossRef]

10. Gross, H.-M.; Boehme, H.; Schroeter, C.; Müller, S.; König, A.; Einhorn, E.; Martin, C.; Merten, M.; Bley, A. TOOMAS: Interactive shopping guide robots in everyday use-final implementation and experiences from long-term field trials. In Proceedings of the 2009 IEEE/RSJ International Conference on Intelligent Robots and Systems, St. Louis, MO, USA, 10-15 October 2009; pp. 2005-2012.

11. Kanda, T.; Shiomi, M.; Miyashita, Z.; Ishiguro, H.; Hagita, N. A communication robot in a shopping mall. IEEE Trans. Robot. 2010, 26, 897-913. [CrossRef]

12. Niemelä, M.; Heikkilä, P.; Lammi, H.; Oksman, V. A social robot in a shopping mall: Studies on acceptance and stakeholder expectations. In Social Robots: Technological, Societal and Ethical Aspects of Human-Robot Interaction; Springer: Cham, Switzerland, 2019; pp. 119-144.

13. Kulyukin, V.; Gharpure, C.; Nicholson, J. RoboCart: Toward robot-assisted navigation of grocery stores by the visually impaired. In Proceedings of the 2005 IEEE/RSJ International Conference on Intelligent Robots and Systems, Edmonton, AB, Canada, 2-6 August 2005; pp. 2845-2850.

14. Shi, C.; Satake, S.; Kanda, T.; Ishiguro, H. How Would Store Managers Employ Social Robots? In Proceedings of the 2016 11th ACM/IEEE International Conference on Human-Robot Interaction (HRI), Christchurch, New Zealand, 7-10 March 2016; pp. 519-520.

15. Shiomi, M.; Shinozawa, K.; Nakagawa, Y.; Miyashita, T.; Sakamoto, T.; Terakubo, T.; Ishiguro, H.; Hagita, N. Recommendation Effects of a Social Robot for Advertisement-Use Context in a Shopping Mall. Int. J. Soc. Robot. 2013, 5, 251-262. [CrossRef]

16. Brengman, M.; de Gauquier, L.; Willems, K.; Vanderborght, B. From stopping to shopping: An observational study comparing a humanoid service robot with a tablet service kiosk to attract and convert shoppers. J. Bus. Res. 2021, 134, 263-274. [CrossRef]

17. Shi, C.; Shiomi, M.; Smith, C.; Kanda, T.; Ishiguro, H. A Model of Distributional Handing Interaction for a Mobile Robot. In Proceedings of the Robotics: Science and Systems, Berlin, Germany, 24-28 June 2013; pp. 24-28.

18. Triebel, R.; Arras, K.; Alami, R.; Beyer, L.; Breuers, S.; Chatila, R.; Chetouani, M.; Cremers, D.; Evers, V.; Fiore, M. Spencer: A socially aware service robot for passenger guidance and help in busy airports. In Field and Service Robotics; Springer: Cham, Switzerland, 2016; pp. 607-622.

19. Joosse, M.; Evers, V. A Guide Robot at the Airport: First Impressions. In Proceedings of the Companion of the 2017 ACM/IEEE International Conference on Human-Robot Interaction, Vienna, Austria, 6-9 March 2017; pp. 149-150.

20. Wang, J.; Meng, M.Q.-H. Real-time decision making and path planning for robotic autonomous luggage trolley collection at airports. IEEE Trans. Syst. Man Cybern. Syst. 2021. [CrossRef]

21. Leite, I.; Martinho, C.; Paiva, A. Social Robots for Long-Term Interaction: A Survey. Int. J. Soc. Robot. 2013, 5, 291-308. [CrossRef]

22. Watanabe, M.; Ogawa, K.; Ishiguro, H. Can Androids Be Salespeople in the Real World? In Proceedings of the 33rd Annual ACM Conference Extended Abstracts on Human Factors in Computing Systems, Seoul, Korea, 18-23 April 2015; pp. 781-788.

23. Shi, C.; Satake, S.; Kanda, T.; Ishiguro, H. A Robot that Distributes Flyers to Pedestrians in a Shopping Mall. Int. J. Soc. Robot. 2018, 10, 421-437. [CrossRef] 
24. Iwamoto, T.; Baba, J.; Nishi, K.; Unokuchi, T.; Endo, D.; Nakanishi, J.; Yoshikawa, Y.; Ishiguro, H. The Effectiveness of SelfRecommending Agents in Advancing Purchase Behavior Steps in Retail Marketing. In Proceedings of the 9th International Conference on Human-Agent Interaction, Virtual Event, Japan, 9-11 November 2021; pp. 209-217.

25. Ogawa, K.; Ono, T. ITACO: Constructing an emotional relationship between human and robot. In Proceedings of the RO-MAN 2008-The 17th IEEE International Symposium on Robot and Human Interactive Communication, Munich, Germany, 1-3 August 2008; pp. 35-40.

26. Al. AITalk. Available online: http://www.ai-j.jp/english (accessed on 4 February 2022).

27. Dahlbäck, N.; Jönsson, A.; Ahrenberg, L. Wizard of Oz studies: Why and how. In Proceedings of the 1st International Conference on Intelligent User Interfaces, Orlando, FL, USA, 4-7 January 1993; pp. 193-200.

28. Satake, S.; Hayashi, K.; Nakatani, K.; Kanda, T. Field trial of an information-providing robot in a shopping mall. In Proceedings of the 2015 IEEE/RSJ International Conference on Intelligent Robots and Systems (IROS), Hamburg, Germany, 28 September-2 October 2015; pp. 1832-1839.

29. Shiomi, M.; Kanda, T.; Howley, I.; Hayashi, K.; Hagita, N. Can a Social Robot Stimulate Science Curiosity in Classrooms? Int. J. Soc. Robot. 2015, 7, 641-652. [CrossRef]

30. Brscic, D.; Kanda, T.; Ikeda, T.; Miyashita, T. Person Tracking in Large Public Spaces Using 3-D Range Sensors. IEEE Trans. Hum. Mach. Syst. 2013, 43, 522-534. [CrossRef]

31. Morales, Y.; Kallakuri, N.; Shinozawa, K.; Miyashita, T.; Hagita, N. Human-comfortable navigation for an autonomous robotic wheelchair. In Proceedings of the 2013 IEEE/RSJ International Conference on Intelligent Robots and Systems, Tokyo, Japan, 3-7 November 2013; pp. 2737-2743.

32. Trautman, P.; Ma, J.; Murray, R.M.; Krause, A. Robot navigation in dense human crowds: Statistical models and experimental studies of human-robot cooperation. Int. J. Robot. Res. 2015, 34, 335-356. [CrossRef]

33. Shiomi, M.; Zanlungo, F.; Hayashi, K.; Kanda, T. Towards a socially acceptable collision avoidance for a mobile robot navigating among pedestrians using a pedestrian model. Int. J. Soc. Robot. 2014, 6, 443-455. [CrossRef]

34. Shiomi, M.; Kurumizawa, K.; Kanda, T.; Ishiguro, H.; Hagita, N. Finding a person with a Wi-Fi device in a crowd of pedestrians. Adv. Robot. 2014, 28, 441-448. [CrossRef]

35. Shiomi, M.; Hagita, N. Finding a person with a wearable acceleration sensor using a 3D position tracking system in daily environments. Adv. Robot. 2015, 29, 1563-1574. [CrossRef]

36. Millán, C.; Fernandes, B.J.; Cruz, F. Human feedback in continuous actor-critic reinforcement learning. In Proceedings of the ESANN 2019 Proceedings, European Symposium on Artificial Neural Networks, Computational Intelligence and Machine Learning in ESANN, Bruges, Belgium, 24-26 April 2019; pp. 661-666.

37. Doering, M.; Brščić, D.; Kanda, T. Data-Driven Imitation Learning for a Shopkeeper Robot with Periodically Changing Product Information. ACM Trans. Hum. Robot. Interact. 2021, 10, 31. [CrossRef]

38. Dazeley, R.; Vamplew, P.; Foale, C.; Young, C.; Aryal, S.; Cruz, F. Levels of explainable artificial intelligence for human-aligned conversational explanations. Artif. Intell. 2021, 299, 103525. [CrossRef]

39. Gunning, D.; Stefik, M.; Choi, J.; Miller, T.; Stumpf, S.; Yang, G.-Z. XAI—Explainable artificial intelligence. Sci. Robot. 2019, 4, eaay7120. [CrossRef] [PubMed]

40. Cruz, F.; Parisi, G.I.; Wermter, S. Learning contextual affordances with an associative neural architecture. In Proceedings of the 24th European Symposium on Artificial Neural Networks, ESANN 2016, Bruges, Belgium, 27-29 April 2016; pp. 665-670.

41. Rahman, Q.M.; Corke, P.; Dayoub, F. Run-Time Monitoring of Machine Learning for Robotic Perception: A Survey of Emerging Trends. IEEE Access 2021, 9, 20067-20075. [CrossRef]

42. Tung, T.X.; Ngo, T.D. Socially aware robot navigation using deep reinforcement learning. In Proceedings of the 2018 IEEE Canadian Conference on Electrical \& Computer Engineering (CCECE), Quebec, QC, Canada, 13-16 May 2018; pp. 1-5.

43. Glas, D.F.; Kanda, T.; Ishiguro, H.; Hagita, N. Field trial for simultaneous teleoperation of mobile social robots. In Proceedings of the 4th ACM/IEEE International Conference on Human Robot Interaction, La Jolla, CA, USA, 9-13 March 2009; pp. 149-156.

44. Shiomi, M.; Kanda, T.; Glas, D.F.; Satake, S.; Ishiguro, H.; Hagita, N. Field trial of networked social robots in a shopping mall. In Proceedings of the 2009 IEEE/RSJ International Conference on Intelligent Robots and Systems, St. Louis, MO, USA, 10-15 October 2009; pp. 2846-2853. 